\title{
EFFECT OF PACKAGING MATERIALS AND STORAGE TEMPERATURE ON QUALITY OF SOME LOCAL FRUIT JUICES \\ Ayat E. Rizk ${ }^{1}$; N. A. Ibrahim ${ }^{1}$; A.M.Alian² and Salwa B. El-Magoli² \\ 1- Food Technology Research Institute Agriculture Research Center, Ministry of Agriculture \\ 2- Food Science and Technology Department, Faculty of Agriculture, Cairo University
}

\begin{abstract}
Recent processed orange, mango and guava juices packed in TetraPack, aluminum, foil plastic and glass containers were collected from the local market and evaluated chemically and microbiologically periodically every two months, during 12 months storage at refrigeration temperature $\left(4^{\circ} \mathrm{C}\right)$ and room temperature $\left(22-27^{\circ} \mathrm{C}\right)$. Results showed that total titrabble acidity (TTA) of the juices decreased in a descending order as follow, aluminum packages, Tetra Pack packages, plastic bottles and glass bottles for juices stored at $4^{\circ} \mathrm{C}$ and room temperature however non-enzymatic browning increased in an ascending order as follows Tetra Pack, aluminum, plastic bottles and glass bottles up to 6 months then started to decrease in the same order. The flavanones content was only affected by the time of storage while the effect of storage temperature and packaging material was quite slight. The material which presented the lowest retention of both ascorbic acid and b-carotene was found to be in glass followed by plastic containers. The aluminum packages presented a poor retention of ascorbic acid. Fruit juice stored at the refrigeration temperature $\left(4^{\circ} \mathrm{C}\right)$ retained the desired quality attributes in juices better than juices stored at room temperature $\left(22-27^{\circ} \mathrm{C}\right)$. Glass bottles gave greater protection against degradation of the chemical attributes of the fruit juices
\end{abstract}

\section{INTRODUCTION}

The food and drink producer is always looking for suitable raw materials and packaging to improve quality and shelf life of the products. Packaging environment established by producers and storage/handling conditions influenced by wholesalers and retailers, effect the quality and subsequent shelf life of juice produced, due to different product-package interactions that take place during storage Plastic packaging is increasingly used for economic reasons. However, it is known that plastic has high oxygen permeability and can absorb some flavour compounds from the food matrix (Ducruet et al., 2001). Furthermore, shelf life is also reduced by degradation of the juice through Maillard reactions that occur whatever the considered packaging materials are believed to be responsible of nonenzymatic browning (Lee and Chen 1998).

The quality of fruit juice depends drastically on vitamin $C$ content; so it is important to find the best suitable storage conditions, although there are other quality parameters such as colour and flavor characteristics that are also very important (Ayhan et al., 2001; ; and 
Zerdin et al., 2003). Vitamin C is an essential nutrient for humans and, because of its high antioxidant power it provides protection against the presence of free radicals participating in the prevention of many diseases (Tannenbaum et al., 1985).

However, and because of its nature, vitamin $\mathrm{C}$ is oxidized and lost during the storage period of the juice. The rate of degradation of the vitamin $\mathrm{C}$ highly depends on the storage conditions (Kabasakalis et al., 2000). Among the factors affecting vitamin $\mathrm{C}$ loss in packed orange juice, temperature, dissolved oxygen and oxygen barrier provided by the container material should be considered. It is well established for instance that low temperatures allow a slower degradation of vitamin C (Ros-Chumillas, et al., 2007). During storage of the juice ascorbic acid is degraded, following two consecutive or parallel pathways, aerobically and an aerobically, at rates depending on storage conditions, packaging and the processing method employed during production (Kennedy et al., 1992; Tawfik and Huyghebaert, 1998).

The objective of this study is to evaluate the effect of different packaging materials (glass, plastic, Tetra Pack and aluminum) and temperature on chemical attributes of orange, mango and guava juices during storage.

\section{MATERIALS AND METHODS}

\subsection{Sample collection and storage}

Four different samples of packaging materials (A, B, C and D) packed with of orange, guava \& mango juice were purchased from the local market. Each sample contained 42 packages, and was divided into two groups. The first group was stored at refrigeration temperature and the second at room temperature for 12 months.

The tested parameters were determined in the freshly manufactured samples of each batch, after as well as 2, 4, 6, 8, 10 and 12 months in the samples stored at $4{ }^{\circ} \mathrm{C}$ and at room temperature $\left(22-27^{\circ} \mathrm{C}\right)$. The mean values of triplicate samples were recorded.

\subsection{Determination of browning index}

The browning index was determined by the method of Meydav et al. (1977).

\subsection{Determination of flavanones}

Juice samples were hydrolyzed by $\mathrm{NaOH}(2 \mathrm{~N})$ for $4 \mathrm{~h}$ at room temperature in the darkness and determined as described by Rouseff et al. (1992).

\subsection{Determination of $\beta$-Carotene}

$\beta$ - Carotene and lycopene were determined according to the method of Nagata and Yamashita (1992).

\subsection{Determination of vitamin $\mathrm{C}$}

Ascorbic acid was estimated using the 2, 6 dichlorophenol indophenol titration method as described by the A.O.A.C. (2000). 


\section{RESULTS AND DISCUSSION}

Effect of storage time, temperature and packaging material on the quality properties of the investigated three local processed fruit juices were studied each two months up to 12 months.

As for the effect of packaging materials, results show that TTA of the juices increased in a descending order as following aluminum packages, Tetra Pack packages, plastic bottles and glass bottles for both juices stored at refrigeration and room temperature as shown in fig.(1). Similar results were obtained by Alaka et al., (2003).

Generally, titratable acidity of stored juices decreased with increasing storage temperature.

Results of fig. (2). Show the effect of packaging material on nonenzymatic browning in fruit juice stored at refrigeration and room temperature. Non-enzymatic browning occurred in juices kept in the four investigated packaging materials. Generally, non-enzymatic browning increased for 6 weeks after which it became constant (Alaka et al., 2003). Non-enzymatic browning increased in a descending order as follows. Tetra Pack, Aluminum, Plastic bottles and Glass bottles. Similar trends were observed in juices stored at refrigeration temperature. Juices stored at room temperature showed higher browning index as indicated in fig. (2). According to Labuza (1996), the extent of non-enzymatic browning in food depends on the food's exposure to oxygen, which in turn depends on the type of packaging material used. Also the extent of non-enzymatic browning in foods depends on storage temperature and time as shown by (Zerdin et al., 2003).

The total content $(\mathrm{mg} / 100 \mathrm{~g})$ of flavanones, shown in fig.(3) ranged from 143-157 in mango juices 140-157 in orange juices and 105-109 in guava juices at the beginning of the storage period. The concentration is in good agreement with previous findings (GilIzquierdo et al., 2002 and Klimczak et al., 2007).

There was a decrease in the amount of the total flavonoid content at the end of the study, after storage in refrigeration and at room temperature. The total content of flavanones, fig.(3), anged from 141-155 in mango juices, 128-145.5 in orange juices and 103-107 $(\mathrm{mg} / 100 \mathrm{gm})$ in guava juice at the end of storage period. Such results are in agreement with those reported by Del Caro et al. (2004) for the total flavonoid content in orange juice after storage at $4^{\circ} \mathrm{C}$,

However, it was clear that the flavanones were not affected by temperature nor with packaging material. The only influence of time which was found to be significant, hence it reached about $7.6 \%$ in orange juices, $1.5 \%$ in guava and $1.4 \%$ in mango juices of total flavanones content after 6-months of storage at both temperatures. Such relatively slight changes in individual and total flavanone content could be explained by the high stability of these compounds 
(Klimczak et al., 2007). According to the literature data, the content of vitamin $\mathrm{C}$ in different juices decreases during storage, depending on storage conditions, such as temperature, oxygen and light access (Kabasakalis et al., 2000 and Zerdin et al., 2003).

After 6 months of storage at $4^{\circ} \mathrm{C}$ for orange, mango and guava juices, the content of vitamin C (fig.4) decreased by $5.33 \%$, $10.97 \%$ and $1.445 \%$, respectively. And after 12 month of storage the decrease was $21.59 \%, 25.59 \%$ and $4.0 \%$, respectively for the same fruit juices. It could be noticed that mango juice was more affected by storage time than orange, meanwhile guava was slightly effected.
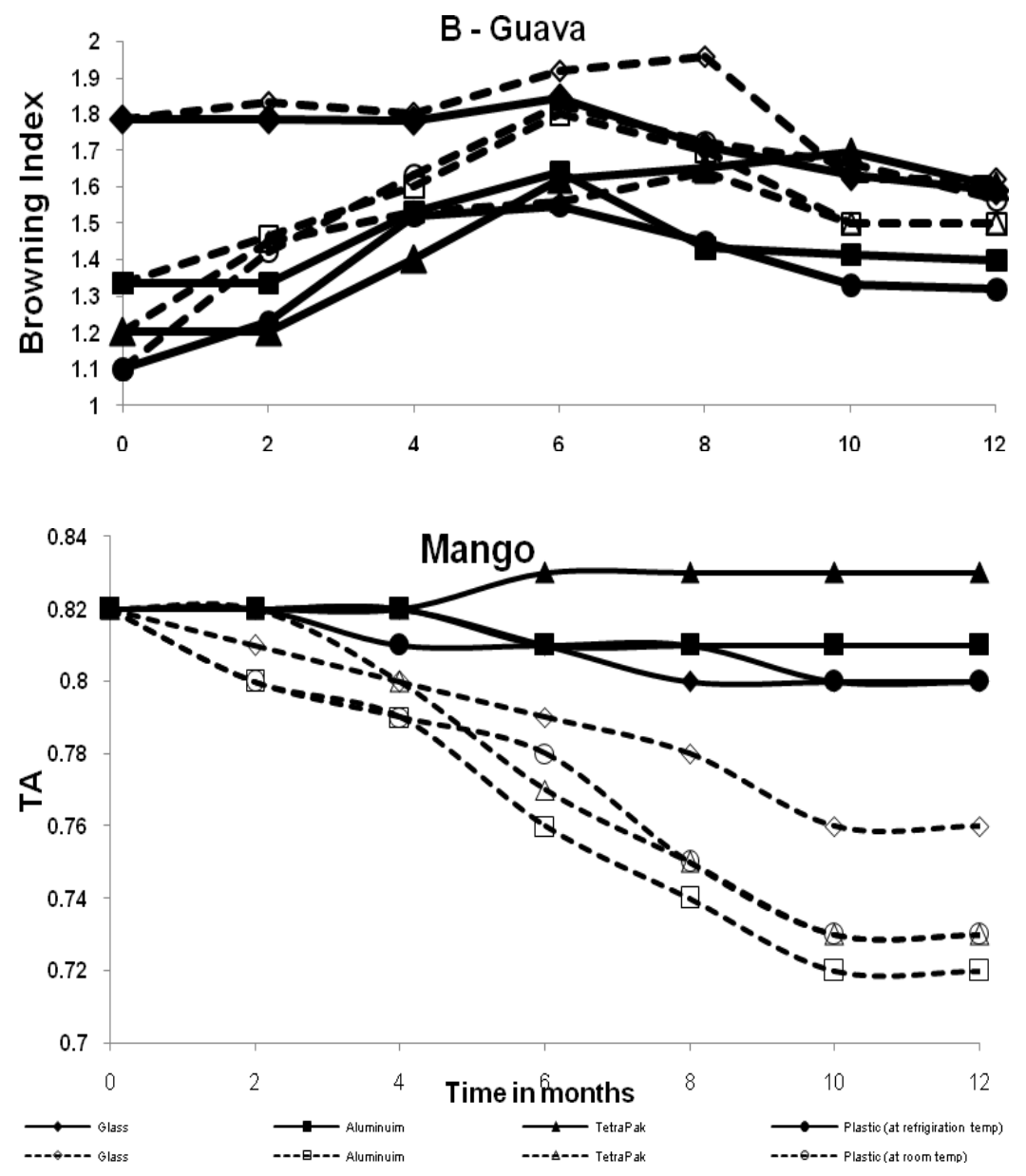

Fig. 1: Effect of storage temperature on total acidity of orange, guava and mango juices. 

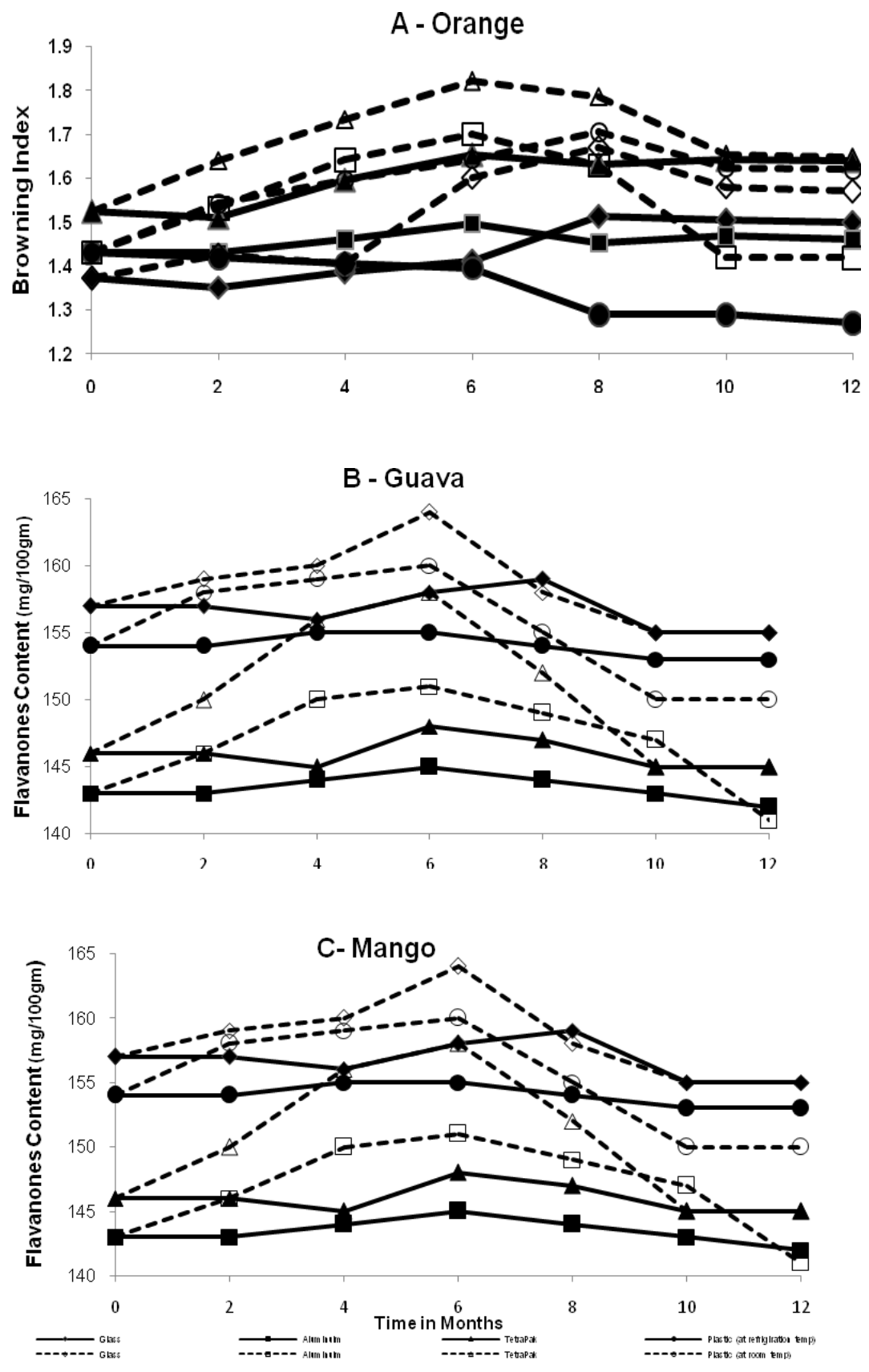

Fig. 2: Effect of storage temperature on browning index of orange, guava and mango juices. 

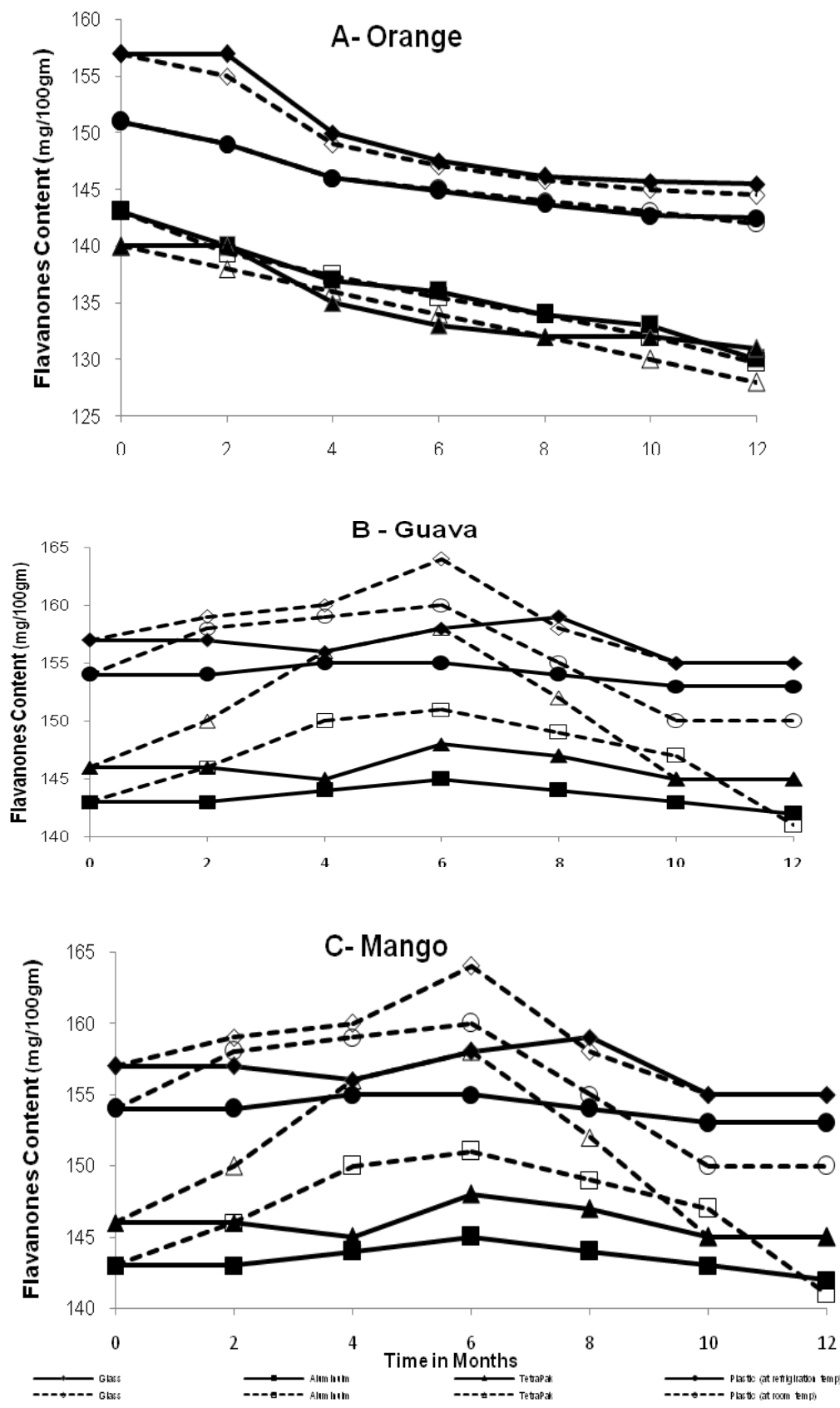

Fig. 3: Effect of storage temperature on flavenones of orange, guava and mango juices. 
J. Agric. Sci. Mansoura Univ., 34 (3), March, 2009
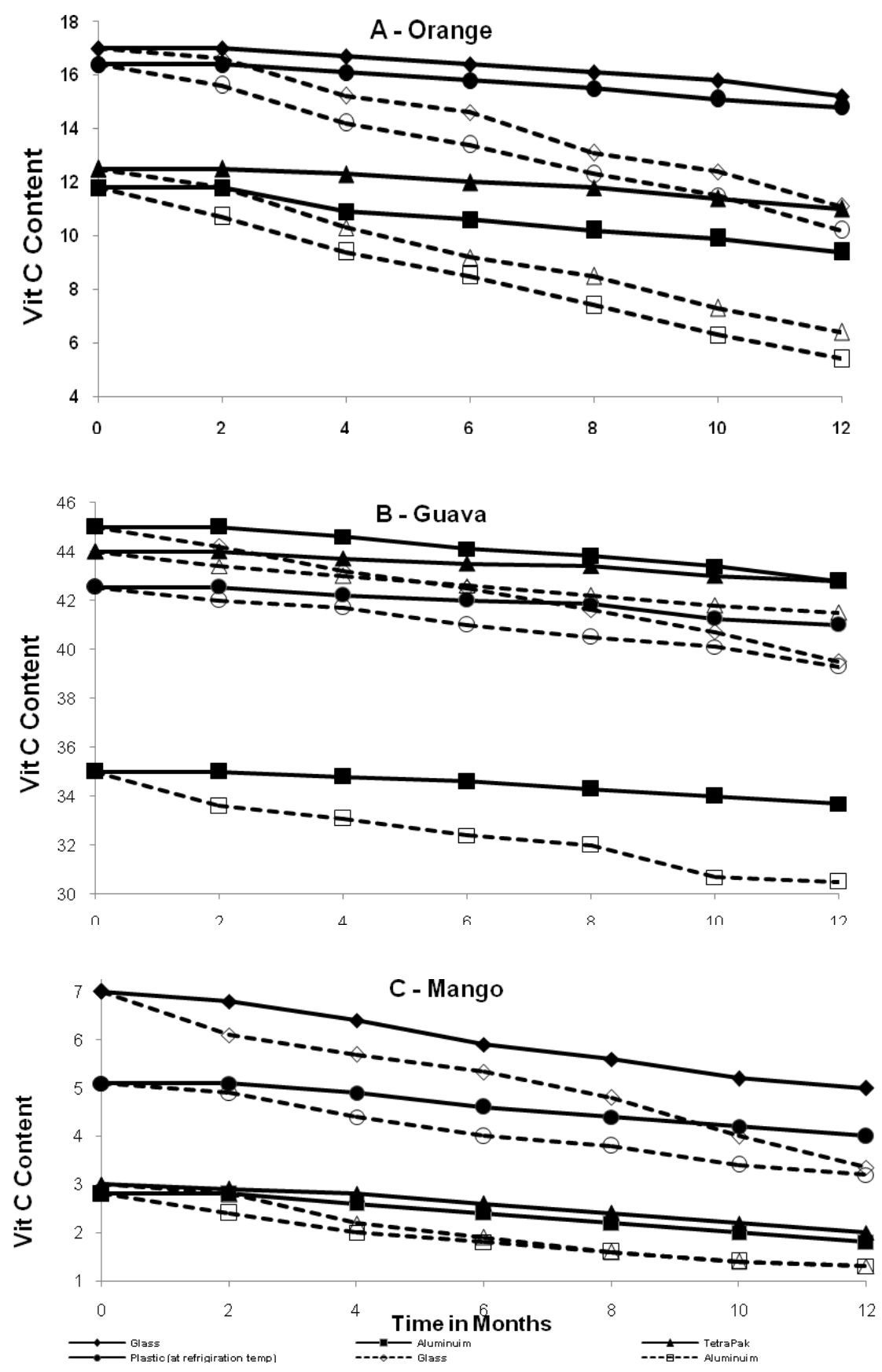

Fig. 4: Effect of storage temperature on Vitamin C of orange, guava and mango juices. 
The results presented are in line with the data obtained by Kabasakalis et al.,(2000) and Arena et al.(2001), who reported a decrease in ascorbic acid content in commercial orange juices after storage at room temperature for 60 days by about $25 \%$.

Data also shows that the increase of temperature to $22-27^{\circ} \mathrm{C}$ caused a distinct decrease in the concentration of vitamin $\mathrm{C}$, the decrease ranged from $4.61 \%$ for guava juice and $21.69,25.94 \%$ for mango and orange juices after 6 months of storage and after 12 month the decrease was 43.88, 42.24 and 8.27 for the same juices respectively.

Alaka et al. (2003) showed that ascorbic acid loss in stored mango juices for only two months was $45 \%$ at $26^{\circ} \mathrm{C}$ and $11 \%$ at $6^{\circ} \mathrm{C}$.

As for the effect of packaging material on percentage V.C loss in fruit juices stored at room temperature, the loss was lower in juices packaged in glass bottles than other packaging materials. Similar trend was observed in juices stored at $4 \stackrel{\circ}{\circ}$. Mango juices stored at room temperature showed ascorbic acid loss of $21.47 \%, 37.25 \%$, 53.75 , and $51.67 \%$ in juices stored in glass, plastic and aluminum and Tetra Pack packages, respectively. Meanwhile mango juices stored at $4 \stackrel{\circ}{\circ}$ showed V.C loss of $11.76 \%, 21.57 \%$ and $35.71,33.33 \%$ in glass bottles, plastic bottles, aluminum and Tetra Pack packages, respectively. The better protective capability of glass bottles may be due to the impervious property of glass to environmental oxygen and exclusion of other components of the environment (Alaka et al., 2003). Kennedy et al., 1992, found that the level of dissolved oxygen present in the sample of commercial single-strength orange juice aseptically processed in TetraBrik cartons after packaging significantly affected the L-ascorbic acid content, the effect being directly related to temperature.

It is clear that packages stored at $4^{\circ} \mathrm{C}$ better preserved V.C in orange juice than those stored at room temperature (fig.4). This result agrees with other authors as Ayhan et al., (2001); and Ros-Chumillas, et al. (2007). The material which presented the best retention of ascorbic acid was glass followed by plastic. The aluminum packages presented a poor retention of ascorbic acid. This is in agreement with other works as those of Ayhan et al., 2001 and Muratore et al., 2005.

The results showed that $\beta$-Carotene content $(\mathrm{mg} / 100 \mathrm{ml})$ ranged from $0.0734-0.0854$ for orange juice, $0.0248-0.0257$ for guava juice and $0.034-0.0367$ for mango juice at the start of the study as shown in fig. (5). Meanwhile at the end of the storage priod the concentrations ranged between $0.0695-0.0820$ for orange juice, $0.0227-0.0247$ for guava juice and 0.0295 - $0.0341(\mathrm{mg} / 100 \mathrm{ml})$ for mango juice after storage at $4 \mathrm{C}$. The decrease was greater after storage at room temperature and ranged between $0.058-0.075$ for orange juice, 0.01681-0.0176 for guava juice and 0.02796 - 0.02937 $(\mathrm{mg} / 100 \mathrm{ml})$ for mango juice. The values were within range of those of Britton, (1995) and Melendez-Martinez et al., (2007). 

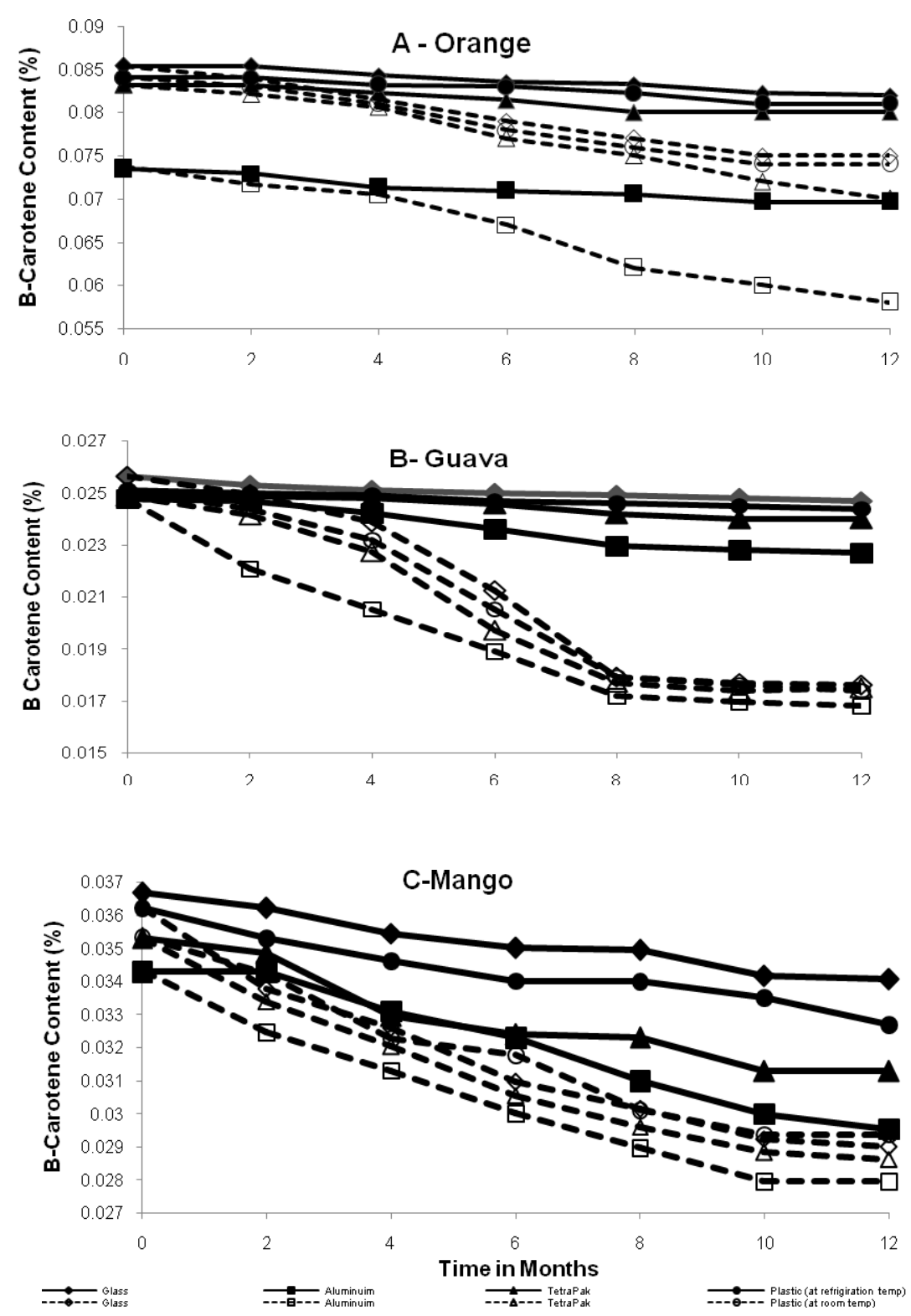

Fig. 5: Effect of storage temperature on $\beta$-carotene of orange, guava and mango juices.

\section{REFERENCES}

Alaka, O. O.; Aina, J.O. and Falade, K. O., (2003). Effect of storage conditions on the chemical attributes of Ogbomoso mango juice. Eur. Food Res. Technol., 218: 79-82 
AOAC (2000) Official Methods of Analysis, Association of Official Analytical Chemists international. Published by the Association of Official Analytical Chemists International. Maryland 208772417, USA.

Arena, E., Fallico, B., and Maccarone, E., (2001). Thermal damage in blood orange juice: kinetics of 5- hydroxymethyl-2furancarboxaldehyde formation. International Journal of Food Science and Technology 36/2: 145-151.

Ayhan, Z., Yeom, H. W., Zhang, Q. H., \& Min, D. B. (2001). Flavor, color, and vitamin $\mathrm{C}$ retention of pulsed electric field processed orange juice in different packaging materials. J. Agric. Food Chem., 49: 669-674.

Britton, G. (1995). UV/Visible spectroscopy. In G. Britton, S. Liaaen-Jensen, \& H. Pfander (Eds). Carotenoids: Spectroscopy (Vol. 1B, pp. 13-63). Basel: Birkhauser.

Del Caro, Piga,, Vacca, and Agabbio., (2004). Changes of flavonoids, vitamin $\mathrm{C}$ and antioxidant capacity in minimally processed citrus segments and juices during storage. Food Chemistry 84, 99105.

Ducruet V., Fournier N., Saillard P., Feigenbaum A., and Guichard E. (2001). Influence of packaging on the aroma stability of strawberry syrup during shelf life. J.Agric. Food. Chem. 49(5), 2290-2297.

Gil-Izquierdo, A., Gil, M.I., and Ferreres, F., (2002). Effect of processing techniques at industrial scale on orange juice antioxidant and beneficial health compounds. Journal of Agricultural and Food Chemistry. 50, 5107-5114.

Kabasakalis, V., Siopidou, D., and Moshatou, E., (2000). Ascorbic acid content of commercial fruit juices and its rate of loss upon storage. Food Chemistry 70, 325-328.

Kennedy, J. F.; Rivera, Z. S.; Lloyd, L. L.; Warner, F. P. and Jumel, K. (1992). L-Ascorbic acid stability in aseptically processed orange juice in TetraBrik cartons and the effect of oxygen. Food Chemistry, 45 (5), 327-331

Klimczak, I. Malecka, M. Szlachta, M. and Gliszczynska-Swiglo, A., (2007). Effect of storage on the content of polyphenols, vitamin $\mathrm{C}$ and the antioxidant activity of orange juices. Journal of Food Composition and Analysis, 20, 313-322.

Labuza,,T.P. (1996). An introduction to active packaging for food. Food Technol. 50(4): 68-71.

Melendez-Martinez, A. J.; Vicario, I. M. and Heredia, F. J. (2007). Provitamin A carotenoids and ascorbic acid contents of the different types of orange juices marketed in Spain. Food Chemistry, 101, 177-184.

Meydev S., Saguy I. and Kipelman I.J. (1977). Browning determination in citrus products. J. Agric. Food Chem., 25 (3), 602-604. 
Muratore, G., Lanza, C. M., Baiano, A., Tamagnone, P., Nicolosi Ausmundo, C., and Del Nobile, M. A. (2005). The influence of using different packaging on the quality decay kinetics of Cucci`a. Journal of Food Engineering, 73, 239-245.

Nagata, M. and Yamashita, I. (1992). Simple method for simultaneous determination of chlorophyll and carotenoids in tomato fruit. Nippon Shokuhin Kogyo Gakkaish, 39(10), 925-928.

Ros-Chumillas, Maria; Belissario, Yulissa; Iguaz, Asuncion and Lopez., Antonio (2007). Quality and shelf life of orange juice aseptically packaged in PET bottles. J of Food Engineering, 79, 234-242.

Tannenbaum, S. R., Archer, M. C., and Young, V. R. (1985). Vitamins and minerals. In O. R. Fennema (Ed.), Food chemistry (2nd ed., pp. 488493). New York: Marcel Dekker.

Tawfik, M. S., and Huyghebaert, A. (1998). Effect of storage temperature, time, dissolved oxygen and packaging materials on the quality of aseptically filled orange juice. Acta Alimentaria, 27(3), 231-244.

Zerdin, K., Rooney, M.L., and Vermue, J., (2003). The vitamin C content of orange juice packed in an oxygen scavenger material. Food Chemistry 82, 387-395.

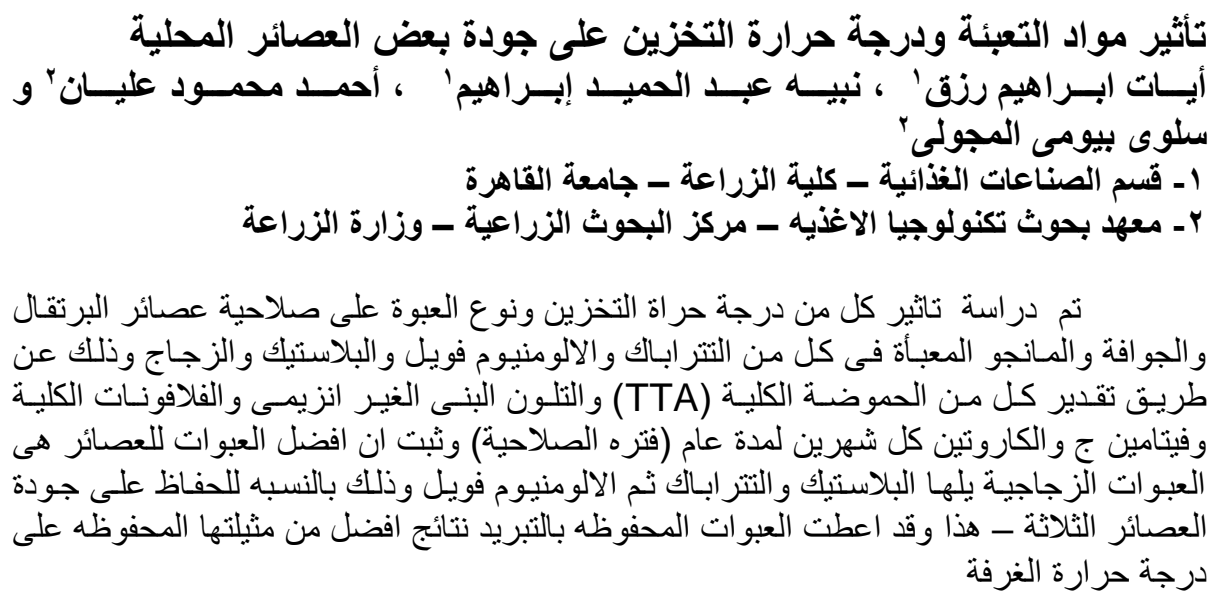

